\title{
Faktor yang Mempengaruhi Waktu Tunggu Pelayanan Kesehatan kaitannya dengan Kepuasan Pasien Rawat Jalan Klinik penyakit dalam RSUD Dr. Iskak Tulungagung
}

\section{Factors Influencing Service Waiting Times in Relation to Internist Clinic Outpatient's Satisfaction at Dr. Iskak Public Hospital Tulungagung}

Torry ${ }^{1}$, Mulyatim Koeswo ${ }^{1}$, Sujianto ${ }^{2}$

${ }^{1}$ Program Studi Magister Manajemen Rumah Sakit Fakultas Kedokteran Universitas Brawijaya Malang

${ }^{2}$ Rumah Sakit Umum Daerah Dr. Iskak Tulungagung

\begin{abstract}
ABSTRAK
Waktu tunggu pelayanan pasien merupakan salah satu indikator kepuasaan pasien dan mutu pelayanan rumah sakit. Laporan capaian kinerja tahun 2014 pada RSUD Dr. Iskak Tulungagung menyebutkan bahwa rata-rata waktu tunggu pelayanan pasien rawat jalan adalah 70 menit, yang melebihi standar pelayanan minimal (SPM) nasional adalah 60 menit. Tujuan penelitian ini adalah untuk mengetahui faktor-faktor yang mempengaruhi waktu tunggu pelayanan kesehatan kaitannya dengan kepuasan pasien rawat jalan dengan menggunakan desain penelitian analisis deskriptif. Data penelitian diperoleh dengan menggunakan pendekatan cross-sectional, yaitu Time and Motion Study dan Survei. Total sampel pada penelitian ini adalah 101 responden yang terdiri dari 101 pasien rawat jalan di Klinik penyakit dalam RSUD Dr. Iskak Tulungagung. Teknik pengumpulan data menggunakan observasi dan kuesioner. Data menunjukkan bahwa total rata-rata waktu tunggu pelayanan rawat jalan penyakit dalam adalah 157,13 menit. Waktu tunggu terpanjang adalah rata-rata rentang waktu tunggu pasien yang telah mendapatkan pelayanan paramedis serta akan dilayani oleh dokter, yaitu 120,07 menit. Hasil analisis regresi berganda menunjukkan bahwa kepuasan pasien dipengaruhi oleh waktu tunggu yang sebenarnya dirasakan pasien, dan kecepatan pelayanan yang diterima pasien $(P<0,05)$. Kesimpulannya, faktor utama yang memperpanjang waktu tunggu pelayanan dan menurunkan kepuasan pasien, adalah kurang optimalnya jadwal dokter bertugas.
\end{abstract}

Kata Kunci: Kepuasan pasien, waktu tunggu pelayanan rawat jalan

\begin{abstract}
Waiting time of patient care is one indicator of patient satisfaction and hospital services quality. Based on Annual Report of Dr. Iskak Tulungagung Public Hospital in 2014, the average service waiting times was 70 minutes which was more than national service standard. The purpose of this study is to determine the factors influencing service waiting times in relation to outpatient satisfaction using descriptive analytic design research. Data were obtained by cross-sectional study using a mixed-method approach such as Time and Motion Study and Surveys. The total sample in this study was 101 respondents consisting of 101 outpatients at internist clinic Dr. Iskak Tulungagung Hospital. Data collection techniques used observation and questionnaires. The data showed that the total average service waiting times was 157.13 minutes. The longest waiting times was the average range of time after paramedic services until waiting time for the doctor which was 120.07 minutes. The results of multiple regression analysis showed that patient satisfaction are influenced by the actual waiting time felt by the patient and the speed of service received by patients $(P<0.05)$. In conclusion, the main factor in the outpatient clinic that may cause prolonged service waiting times and lowering patient satisfaction is the non-optimal doctor schedule.
\end{abstract}

Keywords: Outpatient service waiting times, patient satisfaction

Korespondensi: Torry. Program Studi Magister Manajemen Rumah Sakit Fakultas Kedokteran Universitas Brawijaya Malang, Jl. Veteran Malang Jawa Timur Tel. (0341) 568989Email:torryeen@gmail.com 


\section{PENDAHULUAN}

Pelayanan rawat jalan sering menjadi gerbang pertama akses pasien ke pusat pelayanan rumah sakit (1). Persepsi pasien rawat jalan terhadap layanan kesehatan menjadi indikator penting untuk menilai mutu layanan kesehatan $(2,3)$. Waktu tunggu pelayanan kesehatan yang dirasakan pasien rawat jalan merupakan salah satu indikator kepuasan pasien yang mempengaruhi mutu layanan kesehatan (3). Survei terdahulu oleh Huang menguraikan bahwa pasien rawat jalan di klinik bedah melaporkan cukup puas bila mereka tidak menunggu lebih dari 37 menit sejak pelayanan pendaftaran (4). Penelitian di Uganda pada pasien rawat jalan rumah sakit menjelaskan bahwa lama waktu tunggu lebih dari 2 jam dapat menurunkan kepuasan pasien (5). Waktu tunggu pelayanan kesehatan telah menjadi permasalahan yang terus-menerus terjadi dan memicu ketidakpuasan layanan kesehatan $(1,6)$. Berdasarkan Keputusan Menteri Kesehatan (KMK) No 129 Tahun 2008 tentang Standar Pelayanan Minimal (SPM) (7), waktu tunggu maksimal pelayanan rawat jalan adalah 60 menit yang meliputi waktu yang diperlukan pasien ketika mendaftar hingga dilayani oleh dokter. Beberapa faktor telah diketahui mempengaruhi waktu tunggu pelayanan pasien yaitu tingginya rasio dokter dan pasien, jumlah pegawai yang kurang, jadwal perjanjian pasien dan dokter yang kurang terorganisir, pasien yang tidak memenuhi janji, petugas medis dan paramedis yang terlambat dan kurang perhatian terhadap jadwal yang sudah ditetapkan (8-11). Pada penelitian lain menunjukan faktor utama memanjangnya waktu tunggu rawat jalan pasien adalah prosedur administrasi yang meliputi prosedur atau akses pasien pada pemeriksaan medis dan ketepatan jadwal dokter saat bertugas (12-14). Faktor terpenting yang mempengaruhi ketepatan jadwal dokter saat bertugas di rawat jalan klinik rumah sakit adalah supervisi dokter (15).

Permasalahan waktu tunggu pelayanan di rawat jalan juga ditemukan pada RSUD dr. Iskak Tulungagung. Analisis gap dengan standar pelayanan minimal (SPM) menemukan rerata waktu tunggu 70 menit (SPM: 60 menit). Data keluhan pelanggan juga menunjukkan jumlah komplain terbanyak pada tahun 2014 pada pelayanan rawat jalan (Tabel 1) jauh lebih tinggi bila dibandingkan dengan dua tahun sebelumnya. Kondisi ini dapat dipengaruhi fakta meningkatnya jumlah kunjungan rawat jalan tahun 2014. Pada tahun 2014 jumlah kunjungan rawat jalan adalah 164.585 pasien dan kunjungan Poliklinik Gawat Darurat (IGD) 38.369 pasien, dengan pola semakin meningkat dari tahun 2012 sampai dengan 2014 (Profil RSUD Dr. Iskak Tulungagung tahun 2015). Laporan Tahunan rumah sakit juga menunjukkan rata-rata kunjungan rawat jalan per hari meningkat sejak tahun 2012-2014, dengan kunjungan pada Klinik penyakit dalam (90/584\%) dan Bedah $(102 / 584 \%)$ yang terbesar.

Tabel 1. Komplain masyarakat tahun 2012-2014

\begin{tabular}{|c|c|c|c|c|c|c|c|}
\hline \multirow[b]{2}{*}{ No } & \multirow[b]{2}{*}{ Jenis Komplain } & \multicolumn{2}{|c|}{2012} & \multicolumn{2}{|c|}{2013} & \multicolumn{2}{|c|}{2014} \\
\hline & & $\mathrm{Jml}$ & $\%$ & $\mathrm{Jml}$ & $\%$ & $\mathrm{Jml}$ & $\%$ \\
\hline 1 & $\begin{array}{l}\text { Pelayanan rawat } \\
\text { inap }\end{array}$ & 29 & 19,46 & 9 & 11,54 & 20 & 16,67 \\
\hline 2 & $\begin{array}{l}\text { Pelayanan rawat } \\
\text { jalan }\end{array}$ & 13 & 8,72 & 4 & 5,13 & 33 & 27,50 \\
\hline 3 & $\begin{array}{l}\text { Pelayanan } \\
\text { administrasi }\end{array}$ & 12 & 8,05 & 2 & 2,56 & 5 & 4,17 \\
\hline
\end{tabular}

Tabel 1. Komplain masyarakat tahun 2012-2014 (Lanjutan)

\begin{tabular}{llllllll}
\hline \multirow{2}{*}{ No } & Jenis Komplain & \multicolumn{2}{c}{$\mathbf{2 0 1 2}$} & \multicolumn{2}{c}{$\mathbf{2 0 1 3}$} & \multicolumn{2}{c}{$\mathbf{2 0 1 4}$} \\
\cline { 2 - 8 } & Jml & $\mathbf{\%}$ & Jml & \% & Jml & \% \\
\hline 4 & $\begin{array}{l}\text { Pelayanan IGD } \\
\text { Pelayanan }\end{array}$ & 10 & 6,71 & 4 & 5,13 & 4 & 3,33 \\
5 & 16 & 10,74 & 0 & 0 & 2 & 1,67 \\
$\begin{array}{l}\text { Pavilliun GHD } \\
\text { Pelayanan }\end{array}$ & & & & & & \\
6 & $\begin{array}{l}\text { penunjang dan } \\
\text { kebersihan }\end{array}$ & 26 & 17,45 & 30 & 38,46 & 26 & 21,67 \\
7 & $\begin{array}{l}\text { Pelayanan apotek } \\
8\end{array}$ & 14 & 9,40 & 11 & 14,10 & 14 & 11,67 \\
9 & $\begin{array}{l}\text { Pelayanan Dokter } \\
\text { Pelayanan parkir }\end{array}$ & 11 & 7,38 & 10 & 12,82 & 10 & 8,33 \\
10 & $\begin{array}{l}\text { Pelayanan } \\
\text { keamanan }\end{array}$ & 12 & 8,03 & 4 & 5,13 & 4 & 3,33 \\
\hline TOTAL & $\mathbf{1 4 9}$ & $\mathbf{1 0 0}$ & $\mathbf{7 8}$ & $\mathbf{1 0 0}$ & $\mathbf{1 2 0}$ & $\mathbf{1 0 0}$ \\
\hline
\end{tabular}

Sumber: Data olahan Laporan Tahunan Instalasi Humas RSUD dr. Iskak 2014

Fakta diatas menunjukkan adanya permasalahan waktu tunggu dan kepuasan pasien namun belum dapat dibuktikan apakah faktor waktu tunggu pelayanan pada pasien mempengaruhi kepuasan pasien di RSUD dr. Iskak Tulungagung. Waktu tunggu pada pelayanan rawat jalan merupakan proses yang panjang dan kompleks sehingga perlu dilakukan eksplorasi untuk mengidentifikasi letak dan sebab permasalahan. Penelitian ini dilakukan untuk menggambarkan karakteristik pelanggan, proses pelayanan dan waktu tunggu, serta membuktikan hubungan antara waktu tunggu dan kepuasan pasien. Dengan pendekatan ini data hasil penelitian bisa mengambarkan fenomena secara menyeluruh, karena data digali secara kombinasi dari pasien dan penyedia pelayanan (16). Harapannya, hasil penelitian ini menjadi dasar untuk meningkatkan mutu layanan rumah sakit dalam aspek kepuasan dan waktu tunggu pelayanan pasien.

\section{METODE}

Penelitian dilakukan dengan pendekatan cross-sectional pada bulan Agustus-November 2015 yang menggabungkan metode time and motion study dan survey pada 101 responden pasien di Klinik Penyakit Dalam yang bersedia mengikuti penelitian dengan metode purposive sampling. Pemilihan Klinik Penyakit Dalam sebagai objek kajian berdasarkan pertimbangan proporsi pasien di seluruh Poliklinik RSUD dr. Iskak Tulungagung. Kuesioner survei yang digunakan adalah hasil adaptasi penelitian Herjunianto, et al (18). Observasi time and motion study dilakukan dengan mengamati dan mencatat durasi waktu pada setiap alur pelayanan rawat jalan Klinik penyakit dalam, sejak mendaftar hingga diperiksa dokter $(18,19)$, serta dibantu oleh 2 petugas pendaftaran, 1 petugas distribusi berkas rekam medik, 2 petugas ruang penyimpanan rekam medik, dan 4 perawat rawat jalan klinik penyakit dalam.

Analisis penelitian data survei dianalisis dengan software SPSS versi 23. Karakteristik responden dianalisis menggunakan direct marketing SPSS versi 23, hasil membentuk cluster atau kelompok responden penelitian dengan predictor importance yang bermakna adalah bernilai $\geq 0,5$. Analisis data Time and Motion Study dianalisis dengan Software Microsoft Office Excell, hasil berupa tabel waktu yang menggambarkan waktu terpendek, waktu terpanjang dan waktu rata-rata pada 
setiap titik alur pelayanan rawat jalan klinik penyakit dalam. Hubungan variabel waktu tunggu pelayanan terhadap kepuasan pasien dianalisis menggunakan regresi berganda

\section{HASIL}

\section{Karakteristik Pelanggan Rawat Jalan}

Sebanyak 101 responden terlibat dalam survei. Hasil analisis cluster menampilkan nilai dengan predictor importance yang bermakna, sedangkan detail dapat dilihat pada lampiran 6 . Analisis cluster membentuk 3 kelompok, kelompok terbesar berukuran (50\%) dari total sampel dan terkecil (22\%). Dapat digambarkan bahwa karakteristik dominan pelanggan (50\%) mengunakan pembayaran asuransi, laki-laki yang berumur 55 tahun ke atas dan bekerja wiraswasta. Hanya sebagian kecil (22\%) menggunakan pembayaran umum (out off pocket), wanita berumur 43 tahun ke atas. Semua pelanggan atau pasien berobat kerumah sakit karena rujukan atau kunjungan ulang serta berpendidikan rendah (SD).

\begin{tabular}{|c|c|c|c|}
\hline Cluster & 1 & 2 & 3 \\
\hline Size & & & \\
\hline & $50,0 \%(50)$ & $28,0 \%(28)$ & $22,0 \%(22)$ \\
\hline \multirow[t]{7}{*}{ Inputs } & $\begin{array}{l}\text { Jenis Asuransi } \\
\text { BPJS }(100,0 \%)\end{array}$ & $\begin{array}{l}\text { Jenis Asuransi } \\
\text { BPJS }(100,0 \%)\end{array}$ & $\begin{array}{l}\text { Jenis Asuransi } \\
\text { BPJS }(100,0 \%)\end{array}$ \\
\hline & $\begin{array}{l}\text { Pembayaran } \\
\text { As }(100,0 \%)\end{array}$ & $\begin{array}{l}\text { Pembayaran } \\
\text { As }(100,0 \%)\end{array}$ & $\begin{array}{l}\text { Pembayaran } \\
\text { As }(100,0 \%)\end{array}$ \\
\hline & $\begin{array}{c}\text { Jenis Kelamin } \\
\mathrm{L}(84,0 \%)\end{array}$ & $\begin{array}{c}\text { Jenis Kelamin } \\
\text { P }(100,0 \%)\end{array}$ & $\begin{array}{c}\text { Jenis Kelamin } \\
\text { P }(68,2 \%)\end{array}$ \\
\hline & $\begin{array}{l}\text { Pekerjaan } \\
\text { WS }(44,) \%)\end{array}$ & $\begin{array}{c}\text { Pekerjaan } \\
\text { IRT }(71,4 \%)\end{array}$ & $\begin{array}{l}\text { Pekerjaan } \\
\text { IRT }(59,1 \%)\end{array}$ \\
\hline & $\begin{array}{c}\text { Cara datang } \\
\text { pasien } \\
\text { R K }(94,05)\end{array}$ & $\begin{array}{l}\text { Cara datang } \\
\text { pasien } \\
\text { R K }(100,0 \%)\end{array}$ & $\begin{array}{l}\text { Cara datang } \\
\text { pasien } \\
\text { R K }(59,1 \%)\end{array}$ \\
\hline & $\begin{array}{l}\text { Umur } \\
55,14\end{array}$ & $\begin{array}{l}\text { Umur } \\
51,36\end{array}$ & $\begin{array}{l}\text { Umur } \\
43,41\end{array}$ \\
\hline & $\begin{array}{l}\text { Pendidikan } \\
\text { SD }(32,0 \%)\end{array}$ & $\begin{array}{l}\text { Pendidikan } \\
\text { SD }(42,9 \%)\end{array}$ & $\begin{array}{l}\text { Pendidikan } \\
\text { SD }(45,5 \%)\end{array}$ \\
\hline \multicolumn{4}{|l|}{ eran } \\
\hline
\end{tabular}

\section{Gambar 1. Output SPSS 23 direct marketing survei}

\section{Gambaran Proses Pelayanan dan Waktu Tunggu di Setiap Tahapan Pelayanan}

Pada Tabel 2 dan Lampiran, menunjukan waktu rata-rata pelayanan terpanjang pada titik pelayanan $D$ (menunggu pemeriksaan Dokter) sedangkan yang terpendek pada titik C (kajian oleh perawat). Titik pelayanan D adalah rentang waktu tunggu pasien yang telah dilakukan pemeriksaan awal oleh perawat serta akan dilayani oleh dokter. Titik pelayanan $\mathrm{C}$ adalah rentang waktu pelayanan pasien sejak berkas rekam medik pasien sampai di klinik penyakit dalam, pasien mendapat asuhan keperawanan dan berkas rekam medik siap untuk mendapatkan pelayanan dokter.

Rekapitulasi hasil observasi Time and Motion Study pada Tabel 2 menunjukkan bahwa total rata-rata waktu tunggu pelayanan pasien rawat jalan Poliklinik penyakit dalam, adalah 157,13 menit, lebih besar daripada SPM $(<60$ menit). Waktu terpanjang pada titik pelayanan $D$ (menunggu Dokter) yaitu 120,07 menit. Namun, apabila dicermati waktu rata-rata total pelayanan per unit yang dilakukan petugas sejak pasien mendaftar hingga diperiksa dokter adalah 30,07 menit (mengabaikan proses di titik D), lebih kecil daripada SPM. Menarik untuk dikaji bahwa waktu terpendek pelayanan dapat mencapai hanya delapan menit sedangkan waktu terpanjang hingga lebih dari tujuh jam, menunjukkan variasi pelayanan yang tinggi dan kemungkinan adanya waktu puncak. Fakta lain juga penting dicermati bahwa waktu pemeriksaan baik oleh dokter maupun perawat yang merupakan bagian utama pelayanan hanya memerlukan waktu pendek atau hanya dapat dilaksanakan dala waktu pendek. Gambaran tersebut menunjukkan tingginya waste dari sisi waktu dalam proses pelayanan di klinik penyakit dalam.

Tabel 2. Observasi time and motion study alur pelayanan rawat jalan klinik penyakit dalam 2015

\begin{tabular}{lccc}
\hline & \multicolumn{3}{c}{ Waktu } \\
\cline { 2 - 4 } \multicolumn{1}{c}{ Titik Pelayanan } & $\begin{array}{c}\text { Terpendek } \\
\text { (Minimal) }\end{array}$ & Rata-rata & $\begin{array}{c}\text { Terpanjang } \\
\text { (Maksimal) }\end{array}$ \\
\hline $\begin{array}{c}\text { A (pendaftaran dan pencarian } \\
\text { berkas RM) }\end{array}$ & $00: 00: 10$ & $00: 08: 56$ & $00: 38: 00$ \\
$\begin{array}{c}\text { B (menuju ke klinik) } \\
\text { C (pemeriksaan awal Perawat) }\end{array}$ & $00: 01: 15$ & $00: 12: 29$ & $01: 25: 39$ \\
$\begin{array}{c}\text { D (menunggu pemeriksaan } \\
\text { Dokter) }\end{array}$ & $00: 04: 45$ & $00: 01: 15$ & $00: 02: 15$ \\
E (pemeriksaan Dokter) & $00: 02: 00$ & $00: 07: 27$ & $00: 19: 06$ \\
\hline \multicolumn{1}{c}{ TOTAL } & $0: 08: 18$ & $2: 37: 13$ & (157,13 menit) \\
\hline Total tanpa titik D & $0: 03: 35: 17$ & $0: 30: 07$ & (30,07 menit) \\
\hline
\end{tabular}

\section{Pengaruh Waktu Tunggu Pelayanan Pasien terhadap Kepuasan Pasien}

Prevalensi kepuasan pasien secara umum adalah $97 \%$. Pada analisis regresi linear berganda menunjukkan bahwa variabel bebas secara bersama-sama berpengaruh signifikan terhadap variabel terikat (kepuasan pasien). Hasil analisis per variabel bebas menunjukkan bahwa ada hubungan yang kuat antara waktu tunggu yang dirasakan dengan kepuasan pasien. Kecepatan pelayanan (waktu tunggu aktual) juga menunjukkan hubungan yang kuat dengan kepuasan pasien, sedangkan waktu tunggu yang diharapkan tidak menunjukkan hubungan yang kuat dengan kepuasan pasien. Persamaan regresi yang dihasilkan yaitu $Y=1,916+0,003(X 1)+0,002(X 2)+0,308(X 3)$ dengan kekuatan korelasi variabel secara simultan adalah $21,2 \%$. Sebanyak $18,8 \%$ variasi kepuasan pasien dapat dijelaskan oleh kecepatan pelayanan dan waktu tunggu yang dirasakan (persepsi waktu tunggu). Dari persamaan tersebut, dapat disimpulkan bahwa kepuasan pasien (Y) dipengaruhi secara signifikan oleh waktu tunggu yang dirasakan (X2) dan kecepatan pelayanan (X3) dengan faktor paling dominan adalah kecepatan pelayanan (waktu tunggu aktual). Artinya semakin pendek waktu tunggu aktual dan yang dirasakan maka kepuasaan pasien meningkat (Tabel 3). 
Tabel 3. Hasil uji regresi linier berganda survei responden

\begin{tabular}{lrrrrrr}
\hline Variabel & Koefisien regresi (B) & Std. Error & Beta (B) & $\mathbf{T}_{\text {hitung }}$ & Sig & Keterangan \\
\hline (Konstanta) & 1,916 & 0,247 & & 7,759 & 0,000 & \\
Waktu tunggu diharapkan & 0,003 & 0,003 & 0,096 & 1,039 & 0,302 & Tidak signifikan \\
Waktu tunggu dirasakan & 0,002 & 0,001 & 0,229 & 2,190 & 0,031 & signifikan \\
Waktu tunggu aktual & 0,308 & 0,066 & 0,494 & 4,635 & 0,000 & signifikan \\
R (Koefisien korelasi ganda) & & $=0,461$ & & & & \\
R Square & & $=0,212$ & & & & \\
Adjusted R Square & & $=0,188$ & & & & \\
Fhitung & & $=8,620$ & & & & \\
Ftabel & & $=2,699$ & & & & \\
ttabel & & $=3,182$ & & & & \\
Sig. F & & $=0,000$ & & & & \\
$\alpha$ & & $=0,05$ & & & & \\
\hline
\end{tabular}

\section{DISKUSI}

Profil pelanggan pada Klinik penyakit dalam didominasi oleh peserta BPJS, wiraswasta, lelaki, usia lebih dari 50 tahun dan berpendidikan SD yang menggambarkan masyarakat dari status sosial ekonomi menengah kebawah yang sebagian besar datang dengan rujukan atau kunjungan kembali. Mayoritas responden adalah penduduk di wilayah sekitar RSUD dr. Iskak Tulungagung yang datang dengan rujukan serta bertujuan untuk kontrol penyakit. Meskipun data menunjukkan bahwa terjadi perpanjangan waktu tunggu yang melebih SPM namun responden tampaknya tidak terlalu mempengaruhi kepuasan responden secara keseluruhan terhadap pelayanan RSUD Dr. Iskak Tulungagung. Aspek kepuasan lain bisa jadi lebih mempengaruhi, misalnya fasilitas dan pemeriksaan kesehatan.

Perhitungan melalui Time and Motion Study menunjukkan secara spesifik bahwa total waktu tunggu pelayanan pasien yaitu 157,13 menit yang mana melebihi SPM (<60 menit). Bila dicermati pada diagram time and motion study, waktu tunggu pelayanan pasien sejak pasien mendaftar hingga diperiksa dokter (30,07 menit) lebih cepat dari pada standar nasional (SPM). Fakta ini nampaknya tidak mengurangi kepuasan pasien secara umum terhadap pelayanan di Klinik penyakit dalam RSUD Dr. Iskak Tulungagung. Padahal bila dibandingkan dengan peneliti sebelumnya, memanjangnya waktu tunggu pelayanan pasien menjadi pemicu ketidakpuasan pasien karena mereka merasa tidak diperhatikan dan diperlakukan tidak adil (20). Meskipun waktu tunggu menjadi indikator kepuasan pasien rawat jalan yang mudah dikaji untuk mengetahui kualitas pelayanan, namun waktu tunggu masih belum jelas apakah menjadi proxy indikator untuk mengetahui aspek lain dari kepuasan pasien (21).

Penelitian ini mengeksplorasi faktor-faktor yang mempengaruhi waktu tunggu pelayanan kaitannya dengan kepuasan pasien baik secara survei dan observasi alur pelayanan rawat jalan klinik penyakit dalam. Secara umum, responden merasa puas dengan pelayanan pasien (98\%) yang melebihi SPM ( $\geq 90 \%)$. Bila dibandingkan dengan Laporan Rumah Sakit tahun 2014, maka kepuasan pasien di RSUD Dr. Iskak Tulungagung telah mengalami peningkatan yang signifikan yaitu dari 75,04\% menjadi $98 \%$. Survei ini menunjukkan bahwa kepuasan pasien dipengaruhi oleh waktu tunggu yang dirasakan dan kecepatan pelayanan. Hal ini konsisten dengan penelitian terdahulu yang menyatakan bahwa lamanya waktu tunggu mempengaruhi kepuasan pasien. Semakin lama waktu tunggu pasien maka kepuasan pasien akan semakin turun $(1,3,22,23)$. Disamping waktu tunggu kepuasan pasien juga dibentuk atau dipengaruhi oleh banyak faktor. Faktor lain yang mempengaruhi persepsi kualitas pelayanan rumah sakit yang menjadi dasar minat pasien memilih pelayanan kesehatan, meliputi infrastruktur, kualtias personil, perawatan klinis, prosesdur administrasi, citra rumah sakit, tanggungjawab sosial rumah sakit, dan kepercayaan terhadap rumah sakit $(10,24,25)$.

Salah satu strategi untuk mengurangi waktu tunggu pelayanan adalah merancang sistem perjanjian antara pasien dan dokter $(9,26)$. Penelitian lain pada program optimalisasi supervisi dokter. Supervisi yang efektif terkait waktu tunggu pelayanan mampu meningkatkan kepedulian penyedia layanan kesehatan dan kinerja penyedia layanan kesehatan sehingga proses pelayanan menjadi efisien dan efektif yang pada akhirnya menciptakan kepuasan dan loyalitas pelanggan terhadap rumah sakit $(27,28)$. Hal ini didukung oleh Bosch-Capblanch dan Garner yang menyebutkan bahwa supervisi terhadap penyedia layanan kesehatan mampu meningkatkan kualitas pelayanan kesehatan (29).

Kekuatan utama penelitian ini adalah penelitian yang menyajikan fakta baru dan menggali faktor-faktor yang mempengaruhi waktu tunggu pelayanan pasien rumah sakit untuk memperpendek waktu tunggu pelayanan pasien. Pendekatan penelitian kombinasi pada responden pasien dan proses pelayanan yang diterima pasien, lebih mampu menyajikan faktor-faktor penting yang mendasari bila dibandingkan dengan penelitian tunggal (satu subjek). Meskipun demikian, penelitian ini terbatas pada pasien rawat jalan di Poliklinik penyakit dalam RSUD Dr. Iskak Tulungagung.

Penelitian membuktikan bahwa waktu tunggu aktual dan persepsi waktu tunggu mempengaruhi kepuasan pasien. Besarnya kontribusi waktu tunggu Dokter dalam keseluruhan proses pelayanan dapat dikelola dengan sistem perjanjian mengingat sebagian besar pasien adalah pasien rujukan dan kunjungan ulang. Strategi tersebut diharapkan dapat memberikan kontribusi besar dalam menurunkan waktu tunggu pelayanan di klinik rawat jalan. 


\section{DAFTAR PUSATAKA}

1. McCarthy K, McGee HM, and O'Boyle C. Outpatient Clinic Waiting Times and Non-Attendance as Indicators of Quality. Psychology, Health, \& Medicine. 2000; 5(3): 287-293.

2. Ryan $\mathrm{G}$ and Valverde M. Waiting Online: A Review and Research Agenda. Internet Research. 2003; 13(3): 195-205.

3. Maxwell RJ. Quality Assessment in Health. British Medical Journal (Clinical Research Ed.). 1984; 288(6428): 1470-1472.

4. Huang X-M. Patient Attitude Towards Waiting In An Outpatient Clinic And Its Applications. Health Services Management Research. 1994; 7(1): 2-8.

5. Nabbuye-Sekandi J, Makumbi FE, Kasangaki A, et al. Patient Satisfaction with Services in Outpatient Clinics at Mulago Hospital, Uganda. International Journal for Quality in Health Care. 2011; 23(5): 516-523.

6. Toh LS and Sern CW. Patient Waiting Time as a Key Performance Indicator at Orthodontic Specialist Clinics in Selangor. Malaysian Journal of Public Health Medicine. 2011;11(1):60-69.

7. Menteri Kesehatan Republik Indonesia. Kepmenkes Nomor: 128/Menkes/SK/II/2008 tentang Standar Pelayanan Minimal Rumah Sakit. Jakarta: Menteri Kesehatan RI: 2008.

8. Edward GM, Preckel B, Martijn BS, Oort FJ, de Haes $\mathrm{HC}$, and Hollmann MW. The Effects of Implementing a New Schedule at the Preoperative Assessment Clinic. European Journal of Anaesthesiology (EJA). 2010; 27(2): 209-213.

9. Dexter F. Design of Appointment Systems for Preanesthesia Evaluation Clinics to Minimize Patient Waiting Times: A Review of Computer Simulation and Patient Survey Studies. Anesthesia and Analgesia. 1999; 89(4): 925-931.

10. Padma P, Rajendran C, and Sai LP. A Conceptual Framework of Service Quality in Healthcare: Perspectives of Indian Patients and Their Attendants. Benchmarking: An International Journal. 2009; 16(2): 157-91.

11. Kapustiak J and Ling H. Evaluation of Patient Waiting Times at an Academic Ophthalmology Clinic. The Journal of Medical Practice Management: MPM. 2000; 15(5): 228-33.

12. Reidenbach RE and Sandifer-Smallwood B. Exploring Perceptions of Hospital Operations by a Modified SERVQUAL Approach. Journal of Health Care Marketing. 1990; 10(4): 47-55.

13. Rose RC, Uli J, Abdul M, and Ng KL. Hospital Service Quality: A Managerial Challenge. International Journal of Health Care Quality Assurance Incorporating Leadership In Health Services. 2004; 17(2-3): 146-159.

14. Baldwin A and Sohal A. Service Quality Factors and Outcomes in Dental Care. Managing Service Quality: An International Journal. 2003; 13(3): 207-216.

15. Nurhayani S. Beberapa Faktor yang Berhubungan dengan Kepuasan Kerja Dokter Spesialis di Poliklinik
Rawat Jalan RSU Dr. Kanujoso Djatiwibowo Kota Balikpapan Tahun 2006. [Tesis]. Universitas Diponegoro, Semarang. 2006.

16. Curry LA1, Krumholz HM, O'Cathain A, Plano Clark VL, Cherlin E, and Bradley EH. Mixed Methods in Biomedical and Health Services Research. Circulation. Cardiovascular Quality and Outcomes. 2013; 6(1): 119-123.

17. Herjunianto H, Wardhani V, dan Prihastuty J. Faktor yang Mempengaruhi Cakupan Layanan Farmasi di Instalasi Rawat Jalan Rumah Sakit. Jurnal Kedokteran Brawijaya. 2014; 28(1): 8-14

18. Lopetegui M, Yen PY, Lai A, Jeffries J, Embi P, and Payne P. Time Motion Studies in Healthcare: What are We Talking About? Journal of Biomedical Informatics. 2014; 49: 292-299.

19. Pratiwi AH, Hariyanti T and Susilo S. Pengembangan Alur Pasien dan Berkas Rekam Medis sebagai Optimalisasi Sistem Informasi Rekam Medis. Jurnal Kedokteran Brawijaya. 2015; 28(2): 129-135.

20. Thorne S. Waiting. Waiting. Waiting. The 'Patient' Experience. The Canadian Nurse. 1985; 81(6): 48-49.

21. Hart M. Improving the Quality of Out-Patient Services in NHS Hospitals: Some Policy Considerations. International Journal of Health Care Quality Assurance. 1996; 9(7): 28-38.

22. David D, Hariyanti T, dan Lestari EW. Hubungan Keterlambatan Kedatangan Dokter terhadap Kepuasan Pasien di Instalasi Rawat Jalan. Jurnal Kedokteran Brawijaya. 2014; 28(1): 31-35.

23. Thompson DA, Yarnold PR, Williams DR, and Adams SL. Effects of Actual Waiting Time, Perceived Waiting Time, Information Delivery, and Expressive Quality on Patient Satisfaction in the Emergency Department. Annals of Emergency Medicine. 1996; 28(6): 657-665.

24. Kartikasari D, Dewanto A, dan Saleh MS. Pengembangan Instrumen Penilaian Kualitas Layanan Rumah Sakit. Jurnal Kedokteran Brawijaya. 2014; 28(1): 1-7.

25. Duggirala M, Rajendran $C$, and Anantharaman RN. Patient-Perceived Dimensions of Total Quality Service in Healthcare. Benchmarking: An International Journal. 2008; 15(5): 560-583.

26. Harper PR and Gamlin H. Reduced Outpatient Waiting Times with Improved Appointment Scheduling: A Simulation Modelling Approach. OR Spectrum. 2003; 25(2): 207-222.

27. Kim Y-M, Fiqueroa ME, Martin A, et al. Impact of Supervision and Self-Assessment on Doctor-Patient Communication in Rural Mexico. International Journal for Quality in Health Care. 2002; 14(5): 359-367.

28. Erawati F. Pengaruh Supervisi, Lingkungan Kerja dan Insentive terhadap Kinerja Pegawai (Studi terhadap Account Representative (AR) pada KPP Madya DKI Jakarta). Jurnal Bisnis dan Manajemen Eksekutif. 2014; 1(1): 10.

29. Bosch-Capblanch X and Garner P. Primary Health Care Supervision In Developing Countries. Tropical Medicine \& International Health. 2008; 13(3): 369383. 


\section{Lampiran}

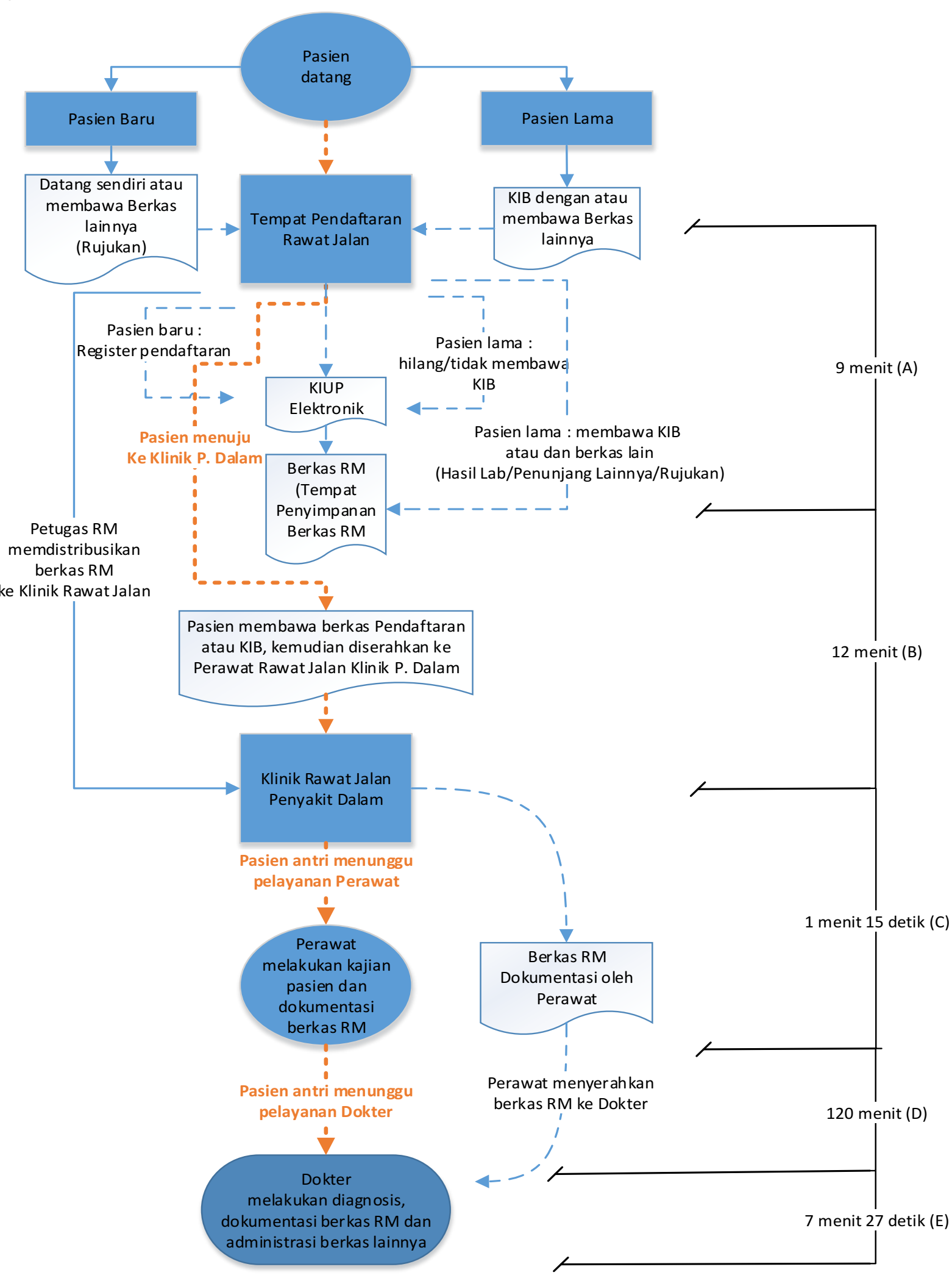

Time and Motion Study responden survei rawat jalan klinik penyakit dalam

Keterangan :

- - Perjalanan pelayanan pasien

- $\rightarrow$ Perjalanan pelayanan berkas pasien

RM: Rekam Medis

KIB: Kartu Identitas Berobat

KIUP: Kartu Indeks Utama Pasien 